\title{
Online Networking and Social Support among Twitter Users at University of Ilorin, Nigeria
}

\author{
Dr. Patrick Udende ${ }^{1, *}$,Dr. Kaior Samuel Akpede ${ }^{2}$, Cynthia Oluwafunmilayo \\ Williams ${ }^{1}$, Dr. Aisha Imam Omoloso ${ }^{1}$
}

\author{
${ }^{1}$ Department of Mass Communication, University of Ilorin, PMB 1515, Ilorin, Nigeria \\ ${ }^{2}$ Department of Mass Communication, Nasarawa State University, Keffi, Nigeria \\ *Corresponding author
}

Received: 02 Dec 2020; Received in revised form: 03 Feb 2021; Accepted: 16 Feb 2021; Available online: 14 Mar 2021 (C)2021 The Author(s). Published by Infogain Publication. This is an open access article under the CC BY license (https://creativecommons.org/licenses/by/4.0/).

\begin{abstract}
Apart from access and ease to use networking sites, online networking is a means to gain knowledge, create and maintain relationships, undertake business transactions, and provides users opportunity to ventilate their psychological and emotional feelings with a view to gaining social support. Against this backdrop, a study was carried out to examine online social networking and social support among Twitter users specifically undergraduates at the University of Ilorin, Nigeria. The objective was to determine the kind of social support Twitter users get through online networking. Anchored on weak ties theory, the study surveyed 310 respondents from a study population of 1,611 based on the Krejche and Morgan (1970) published table from all the fifteen Faculties at the University of Ilorin. The Google questionnaire was used as instrument of data collection. Findings revealed that respondents seeking social support on Twitter gain primarily financial, entertainment and moral support. The study also revealed an insignificant correlation between the levels of following on Twitter and the magnitude of social support gained. Based on these findings, this study recommended among other things, sustained use of Twitter by users to seek social support.
\end{abstract}

Keywords-online networking, social support, twitter users, undergraduates, weak ties.

\section{INTRODUCTION}

A shift in social relations marked the advent of the Internet which facilitates actualization of the world as a global village. The Internet and its corresponding networking sites that broaden media ecology have, therefore, redefined their status. They are no longer mere tools of deriving information but veritable tools for human interaction. These contemporary interactive communication channels enable people of different social strata especially undergraduates to connect to one another, seek for support, share ideas, experiences, pictures, messages and information of interest. Ellison and Boyd (2013) construe social networking sites as Web based services that allow individuals to construct a public within a bounded system that articulate a list of 
other users with whom they share a connection and, view and traverse their list of connections and those made by others within the system. Thus, the natural physical barrier that characterized human networking is blurred thereby facilitating the rapidity and quantum of networking people of near and distant settings make.

In recognition of usefulness of networking sites, Onomo (2012) remarks that they have become widespread tools for communication and exchange of ideas, helping individuals and organizations with just causes to reach a phenomenally vast audience that could hitherto not be reached by traditional media.S ome of these networking sites include Facebook, WhatsApp, Wechat, Tunmblr, Instagram, Twitter, Google+, Baidu, Skype, Sina Weibo, Line, Snap chat, Pinterest, LinkedIn, Telegram, Reddit. Even as they are numerous, these networking sites are not equitably used across countries. Still, even within a country, while some are predominantly used, the same cannot be said of others. The disproportionate use of social networks is premised on their presence and more importantly, the alluring features meant to suit the different interests of their users.In Nigeria, almost all the aforementioned networking sites are used but in disproportionate magnitude with Twitter among the dominant ones.

Twitter, which is a micro blogging service, emerged as a medium in spotlight through its features. Unlike most online networking sites, such as Facebook or MySpace, the relationship of following and being followed requires no reciprocation. A user can follow any other user, and the user being followed needs not follow back. Being a follower on Twitter means that the user receives all the messages otherwise known as tweets from those the user follows.

Since inception of the Internet and online networking sites, Twitter has attracted numerous users, many of whom using it as part of their daily activities. Twitter, like other social networking site are used through computer alone while others are used with mobile phones. Florunso, Vincent, Adekoya and Adewale (2010) present a larger picture that, in Africa, online networking sites are becoming widely spread than they have ever been before and it appears that people's perception of this technology varies. Nigeria, being the most populous African country with high number of students with high propensity to use social networking sites and specifically Twitter is doubtless. These online networks especially Twitter do not only serve as tools for entertainment, leisure, business transaction, and academic activities, but also tools for assisting and impacting other members of the society physically, emotionally and psychologically.

To the extent that social networking sites are beneficial, users often read stories of people's misfortune but more importantly their attainment through the publicity (social support) given to them through these online networks. Scholars have, however, characterized social networks to be of more harm than good to their users. They link their reservation to the fraudulent activities of users, mischievous posts, time users invest to consume them, and the degraded quality of information they exchange.

Meanwhile, a scan on literature shows that even as abundant literature exists on online networking and social networking sites, such studies are skewed to definition, history and scholarship (see Boyd, \& Ellison, 2007), perception of users towards social networks (see Ngozi. \& Mustapha, (2019; Manca \& Ranieri, 2013), how information is shared on social networking sites (see Folorunso, Vincent, Adekoya, \& Adewale, 2010), uses of online network (see Bello, Inuwa-Dutse, \& Heckel, 2020; Apuke \& Ayih, 2020), and increased peer support and communication about course content and assessment(see DirVall \& Kirwin, 2012)without premium placed on social support. Where literature shows an indication of social media use and social support, the thrust is on older citizens or a narrative review and direction for future research, most of which are foreign rather than situating it in Nigeria (see Meng, Martinez, Holmstrom \& Chung, 2016). This creates a research gap that this study seeks to fill. In order to carry out this study, the following four research questions were used as a guide:

\section{ISSN: 2456-7620}


RQ1: What is the pattern of online networking among undergraduates Twitter users?

RQ2: What are the reasons for online networking among undergraduates Twitter users?

RQ3: What social support undergraduates Twitter users seek on online networking?

RQ4: What kind of relationship exists between online social networking and social support among undergraduates Twitter users?

\section{THEORETICAL FRAMEWORK}

The study makes use of the theory of weak ties otherwise known as theory of strength of weak ties, which is one of social network theories that views social relationships in terms of nodes and ties. Nodes are the individual actors within the networks while ties are the relationships between the actors (Wei, Xu, Wang, Dong, Wang \& Fang, 2016). Credited to the seminal work of Granovetter (1973) and developed by Kavanaugh and Reese (2005) and Easley and Kleinberg (2010), the theory focuses on the role of weak social ties in diffusing ideas and information. Weak ties in this context mean social relations that require little investment, and they consist mostly of acquaintances or other loosely connected people rather than kin or close friends. Forms of weak social ties include "add friends," " follow the post," "mention," and "retweet".

The hallmark of the theory is that people get information and support through their weak social ties, as opposed to relying on their family or close friends. This is based on a combination of factors that strengthen social ties, such as the duration of interaction, the amount of effort individuals invests in a relationship, the extent to which the social ties provide reciprocal utility (e.g. social support), and the level of intimacy exchanged in a relationship (Liu, Sidhu, Beacom,\& Valente, 2017). The justification to suggest why weak ties are more likely to channel novel information and ultimately, social support than strong ties brings to mind the network concept that emphasizes bridging or social connections that link two otherwise unconnected network clusters as presented in Fig.1.

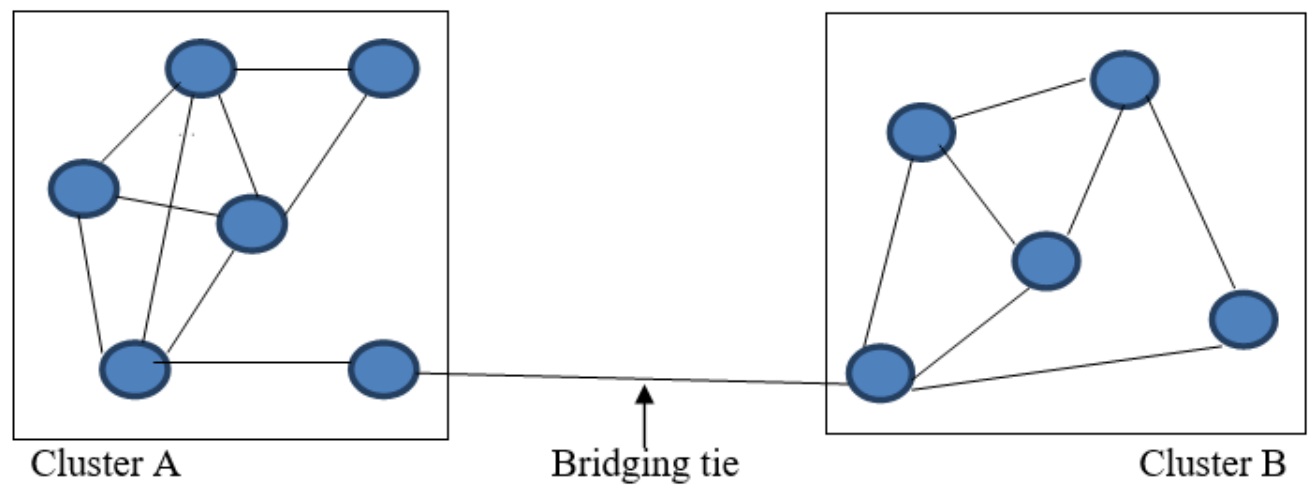

Fig. 1: Bridging ties

Source: Liu, Sidhu, Beacom and Valente (2017, p.5)

As presented (in Fig.1), it is assumed that each network cluster represents a circle of close friends. Linking those constituting members in each of the clusters are nodes. Similarly, the nodes bridge those people that make-up other clusters, who may not necessarily be friends or family members, but for the fact that they network with people familiar with one using social network. This qualifies the user to indirectly network with those s/he may be unfamiliar with physically. Easley and Kleinberg (2010) argue in this direction that if two people in a social network have a friend in common, then there is an increased likelihood that they will 
become friends themselves at some point in the future; what is referred to as triadic closure. In such highly interconnected circles, each person is likely to receive a similar set of information. This is clearly demonstrated by the bridging tie (sitting between the two clusters), which becomes the only opportunity for any nodes in Cluster A to access novel information from Cluster B. This does not rule out the family ties which are also often known of providing redundant information. As Granovetter (1973), argues based on findings of his study that weak ties were more likely to be bridging ties, because weak ties' peripheral position made them better able to reach outside information than strong ties. Thus, the strength of weak ties, therefore, is not about the number of connections. Rather, it lies in the ability of weak ties to reach a broader, and potentially more heterogeneous, set of information sources. Researchers (Maness, 2017; Li, Sheng. \& Wei, 2015; Harone, 2014; Easley \& Kleinberg, 2010; Kavanaugh \& Reese, 2005) have differently used the weak ties theory which proves to be effective.

The applicability of weak ties theory to this study can be seen from the prism of the emergence of Internet and social networking sites which has created an increase in online weak ties that provide novel platforms through which individuals connect with geographically distant others, beyond their family members and friends. This is fundamental when weighed on the scale of the profound roles networks play in bridging the local and global.

\section{ONLINE NETWORKING AND SOCIAL SUPPORT}

A twist to the traditional networking (the act of meeting and associating with people and making connections with individuals to strengthen one's structure in diverse ways) is its alternate online networking. Online networking can be broadly defined as internet or mobile-based social spaces designed to facilitate communication, collaboration, and content sharing across networks of contacts (Hitwise, 2007). These mobile-based social spaces are changing the ways in which people use and engage with the internet and with each other. Young people particularly are quick to use the new technology in ways which increasingly blur the boundaries between their online and offline activities (Hitwise, 2007). Online networking is also developing rapidly as technology changes with new mobile dimensions and features (Boyd, 2008). Permissions are a very important feature of most online networking. They allow members and groups to control who get access to their profiles, information, connections and spaces, as well as degrees of access. Through these combinations of permissions and privacy, users can manage a range of different relationships online, as well as manage their online presence. That is how they appear to friends, acquaintances, or the general public. Managing relationships online and managing online presence are central to having fun with and using social networks safely.

Social networking sites which leverage online networking offer ample features including content sharing, pictures, search engines, and profile-based services or micro blogging services commonly associated with Twitter. Profile-based services are primarily organized around members' profile pages which primarily consist of information about an individual member, including their picture, interests, likes and dislikes. This way, users develop their space in various ways, and can often contribute to each other's spaces typically leaving text, embedded content or links to external content through message walls, comment or evaluation tools. Users often include third-party content (in the form of "widgets") in order to enhance their profiles, or as a way of including information from other web services and social networking services.

Micro-blogging services allow users to publish short messages publicly or within contact groups. They are designed to work as mobile services, but are popularly used and read on the Web as well. Many services offer "status updates", short messages that can be updated to let people know what mood the user is in or what the user is doing. These can be checked within the site, read as text messages on phones, or exported to be read or displayed elsewhere (Lew, 2007). They

\section{ISSN: 2456-7620}


engage users in constantly updated conversation and contact with their online networks.

Social support is the tangible and intangible assistance people seek and or get from those they network with. It may also be defined as the perception or reception of coping assistance or as attributes of one's social circle (Uchino, 2004). Perceived support means the extent to which a social support seeker believes of the availability of the desired support from people connected to. This diametrically opposes actual or enacted supportive actions provided or received from those people network with. Irrespective of the assistance, tangible or intangible, social support is linked to the positive benefits of an individual seeking it and it increases greatly. Gottlieb and Bergen (2010) categorize social support into emotional, informational, esteem, tangible, and network support.

Against the backdrop that people naturally connect physically or online, the social support they seek is inadvertently an inalienable feature of the social network. Those people connected to include family members, friends, acquaintances, colleagues at work place, sub-ordinates, superiors, business associates and even those that may be unfamiliar and loosely connected. As such, people linked with may be willing and ready to assist those seeking support (Donev, Pavlekovic \& Lijana, 2008). Consequently, those who enjoy strong social ties are likely to be at low risk of psychological and physical impairment, unlike those with low social ties.

Given the ubiquity of online networking in people's daily life and its potentially important role in the seeking, reception, and provision of social support (Meng, Martinez, Holmstrom \& Chung, 2016), people are inclined to connect with others online to reap the benefits derived from the online outlet.

\section{CONTEXTUALISING TWITTER}

Twitter is an online social networking and micro blogging service that enables users to send and read "tweets", which are text messages limited to 140 and
280 characters depending on the recognized popularity of the specific Twitter user. Registered users can read and post tweets but unregistered users can only read them. Created by Jack Dorsey, Evan Williams, and Biz Stone in 2006, users access Twitter through the website interface, SMS, or mobile device apps. It is now one of the ten most visited websites, and has been described as the SMS of the Internet. As of September 2013, the company's data showed that 500 million users send over 400 million tweets daily, with nearly $60 \%$ of tweets sent from mobile devices (Moore, 2013). Twitter possesses the following features:

i. Tweets: Tweets are messages sent out over the Twitter network. They are publicly visible by default, but senders can restrict message delivery to followers only. Users can tweet via the Twitter website, compatible external applications (such as for smart phones), or by Short Message Service (SMS) (Drew, 2012). While the service is free, accessing it through SMS may incur phone service provider fees. Users may subscribe to other users' tweets known as following or tweets, a portmanteau of Twitter and peeps (Hoffman, 2012). The users can also check the people, who are unsubscribing them on Twitter (unfollowing) via various services (Douglas, 2012). In addition, users have the capability to block those who have followed them. Also, users are allowed to update their profile via their mobile phone either by text messaging or by apps released for certain smart phones and tablets.

ii. Format: Users can group posts together by topic or type by use of hash tags. Hash tags are words or phrases prefixed with a "\#" sign. Similarly, the "@" sign followed by a username is used for mentioning or replying to other users (Fred, 2007). To repost a message from another user and share it with one's own followers, RT symbolizes the re-tweet function in the message. The tweets were set to a largely constrictive 140 to 280-character limit for compatibility with SMS messaging, introducing the shorthand notation and slang commonly used in SMS messages.

iii. Trending Topics: A word, phrase, or topic that is tagged at a greater rate than other tags is said to 
be a trending topic. Trending topics become popular either through a concerted effort by users, or because of an event that prompts people to talk about one specific topic (Balanarayan, 2009). These topics help Twitter and their users to understand what is happening in the world. Trending topics are sometimes the result of concerted efforts and manipulations by preteen and teenaged fans of certain celebrities, breaking events or cultural phenomena, particularly musicians. There have been controversies surrounding Twitter trending topics: Twitter has censored hashtags that other users found offensive.

iv. Mobile: The mobile version of Twitter, m.Twitter.com, has a couple of mobile apps for iPhone, iPad, Android, Windows Phone and BlackBerry. There is also a version of the website for mobile devices, SMS, and MMS services.

v. Interface: On April 30, 2009, Twitter adjusted its web interface, adding a search bar and a sidebar of "trending topics" the most common phrases appearing in messages. Biz Stone, Twitter co-founder, explains that all messages are instantly indexed and that with this newly launched feature, Twitter has become something unexpectedly important; a discovery engine for finding out what is happening right now (Biz, 2009).

Some influencers affect how people use Twitter. Their influence manifests as reply, mention, retweet, and homophily. Homophily is a tendency that a contact between similar people occurs at a higher rate than among dissimilar people (McPherson, Smith-Lovin \& Cook, 2001). A user will interact more with another user, who shares perceived similarity in the type of people followed and, tweets made. Weng, Lim, Jiang and $\mathrm{He}$ (2010) have reported that two users, who follow reciprocally, share topical interests. Homophily occurs in two contexts: geographic location and popularity.

\section{BENEFITS OF ONLINE NETWORKING}

The benefits of online networking are foremost; to develop and optimize users' potentials and realize their material, emotional and psychological needs. It also gives users the opportunity to increase number of people to network with. This means the ability to connect people with others with related interests and goals. Barker (2013) captures the benefits in two ways the first being web engagement (use of social networking sites to interact with their peers and even teachers about classrelated subjects and for important businesses). The second benefit is provision of informal knowledge (facilitating learning and skill development outside formal learning environments by supporting peer-topeer learning of knowledge and skills collaboration, and online marketing).

In the educational realm, networking is especially helpful if one needs letters of recommendation and has to rely on their numerous people, who know their goals and initiatives, and are likely to write the letter of recommendation (Kathy, 2011). To further stretch the benefit of Twitter as a social networking site, Konetes and McKeague (2011) reveal that, students use Twitter and other channels to develop their identities, beliefs and stances on various issues such as politics, religion, and work, as well as to pioneer and develop intimate relationships.

The benefits of online networking are amplified by Siemens and Weller(2011), who posit that it makes possible the blending of personal and professional lives, which help stimulate peer-to-peer conversations, distribution and diversity of expertise, information- and resource-sharing, and the development of communication competencies, where people are writing for multiple, authentic audiences as opposed to merely their class or teacher.

In addition, Notley (2009) explains that social networking helps in the school and universities to leverage and complement formal education activities and enhances learning outcomes. This can only be possible when users exploit the opportunities social networking offers for new relationships as well as strengthening existing relationships.

\section{ISSN: 2456-7620}




\section{DANGERSOF ONLINE NETWORKING}

Online social networking has stifled face-to-face contact with individuals, families, groups and students. In contemporary times most users, prefer to communicate through the networking sites rather than through face-toface contact leading to preference of online networkin gas a socializing force.

Ahmed (2011) cited in Omekwu, Eze and Odoh (2014) report that one of the dangers of online networking is the heightened cybercrime or e-crime it encourages. Users indiscriminately post messages without regard to the content.

Another drawback to online networking is the tendency for some users to simply share too much information leading to people's loss of their jobs or friendship over leaking information on social networking. Even if a user of a social site has her privacy settings of highest level, their information can still be passed on by someone on their friends' list. It does not take much for an angry follower to copy and paste a status if they are looking for revenge. Furthermore, there has been a recent increase in phishing attacks associated with social media sites (Fisher, 2011). The attacking phishing messages may appear to come from someone that the victim knows. Having obtained long information for a few accounts, scammers will then send out messages to everyone connected to the compromised accounts, often with an enticing subject line that suggests familiarity with the victim (Baker, 2009).

Due to the fact that Twitter creates the illusion of familiarity and intimacy on the internet, the result is that people may be inclined to share information on which they would have preferred to keep private. Again, cross site request forgery (CSRF) is an attack which causes an end user's web browser to execute actions of the attacker's choosing without the user's knowledge. By embedding a malicious link in a web page or sending a link via email or chat, an attacker may cause the users of a web application to perform unwanted actions. More specifically, the attack causes the user's browser to make requests to a web site to which it has been authenticated, without the user's or the web site's knowledge. These actions may result in compromised end user data operations, or even an entire server or network.

\section{STRATEGIES TO COMBAT DANGERS OF ONLINE NETWORKING}

Several authors have suggested many strategies for the amelioration of the danger of online networking. According to SANs (2009) cited in Omekwu, Eze and Odoh (2014), threat from insufficient authentication controls could be mitigated by the password security portion of an organizational security policy. In many social media, applications of data are distributed in various locations. So, password security would help offset these risks. Password security is a crucial part of a recommended security policy. Good password security would make it much harder for an attacker to gain access to a protected account or database. Another important aspect of password policy is using strong password. This is why it is necessary for users to choose strong passwords that they can memorize without having to write them down somewhere they could be exposed.

It is important that users should be aware of phishing attacks. As Timm and Perez (2010) note that in online networking, users are often quick to accept messages purporting to be from friends or acquaintances at face value without validation. Such messages often have enticing subject lines or contents leading users to perform actions desired by the attacker, such as opening attachments or running applications. Timm and Perez (2010) are emphatic that in order to avoid disclosing information to an imposter, users should follow some prudent practices when communicating on social networking sites. Primarily, users should exercise basic caution when communicating and sharing information with online friends.

Similarly, Rosman (2009) amplifies the essence of a secured account that security in social networking site starts with knowing to whom one is communicating. Many people have friends and following online, but do

ISSN: 2456-7620

https://dx.doi.org/10.22161/ijels.62.12 
not really know who their online friends are or whether they are even whom they claim to be. This makes them vulnerable to mischievous users.

\section{METHODOLOGY}

A survey was conducted with questionnaire as instrument of data collection. The questionnaire was structurally based mainly on Likert Scale 5-option. All the items in questionnaire were close-ended. Population of the study was 1, 611 undergraduates Twitter users out of the entire 43,983 undergraduates at the University of Ilorin, Nigeria. Out of the 1, 611 Twitter users identified through Google questionnaire, a sample of 310 respondents was drawn using the Krejcie and Morgan (1970) published table. In order to harvest data, an online questionnaire was posted for Twitter users to complete. The questionnaire was configured to stop when the pre-determined number of 310 sample was recorded. Data was analyzed using the Statistical Package for Social Science (SPSS) web 2.0 Version and expressed in tabular form in simple percentages and mean deviation.

\section{DATA ANALYSIS AND PRESENTATION}

Data analysis and presentation was based on the 310 copies of the questionnaire. The major demographic characteristics in this study were respondents' age, sex, level of study, religion, and marital status. Most (36.8\%) respondents were 400 Level with female respondents in the majority (68.3\%). Age wise, majority (50.5\%) within age bracket 16-20 constituted the respondents. There were slightly more Christian Twitter users (55.5\%) than their Muslims and Traditionalists counterparts. An overwhelming number (91\%) were single.

RQ1: What is the pattern of online networking among users on Twitter?

The pattern includes frequency of usage, duration of use, level of activeness on Twitter (in terms of tweeting and re-tweeting), and the number of followers the respondent has on Twitter.

Table 1: Patterns of online social networking among Twitter users

\begin{tabular}{lll}
\hline Patterns of online social networking use & Frequency & Percentage \\
\hline How often you use Twitter & 38 & 12.2 \\
Never & 72 & 23.2 \\
Rarely (1-2 days) & 80 & 25.8 \\
Sometimes (3-4 days) & 60 & 19.4 \\
Often (5-6 days) & 60 & 19.4 \\
Always (7 days) & $\mathbf{3 1 0}$ & $\mathbf{1 0 0 . 0}$ \\
Total & & \\
Hours spent on Twitter daily & & 24.8 \\
30 minutes & 77 & 27.7 \\
1 hour & 86 & 19.3 \\
3 hours & 60 & 18.0 \\
Mours & 56 & 10.0
\end{tabular}


Total

How active are you on Twitter

Non active user

Active user

Very active user

Undecided

Total

How many followers on Twitter

Less than 500 followers

500 - 1000 followers

1000 - 5000 followers

More than 5000 followers

Total
95

83

310

100.0

30.6

102

26.7

30

.6

310

100.0

164

52.9

92

29.6

39

12.5

15

4.8

310

100.0
Table 1 shows that most respondents $(25.8 \%)$ use Twitter between 3 and 4 days on the average. On the other hand, most respondents (24.8\%) use Twitter averagely for 30 minutes the same way those who use the micro blogging platform for 1 hour on the average. Result on level of activeness on the platform in terms of tweeting and re-tweeting shows that 102respondents representing (32.9\%) were very active users on Twitter, followed by 95 respondents $(30.6 \%)$, who were nonactive users. On followership, majority of respondents (55.8\%), had less than 500 followers as opposed to insignificant 15 respondents translated to $4.8 \%$ with more than 5000 followers.

RQ2: What are the reasons for online social networking among Twitter users?

To find out the reasons for online social networking among undergraduate students of the University of Ilorin, who are Twitter users, a 14-item 5-point Likert scale was developed and was required to be filled by the respondents. Table 4.2 presents the reasons for online social networking among Twitter users.

Table 2: Reasons for using Twitter

\begin{tabular}{|c|c|c|c|c|c|c|c|c|}
\hline \multirow{2}{*}{$\begin{array}{l}\text { Reasons for using } \\
\text { Twitter }\end{array}$} & \multicolumn{5}{|c|}{ Level of Agreement* (\%) } & \multirow[b]{2}{*}{$\mathbf{M}$} & \multirow[b]{2}{*}{ SD } & \multirow{2}{*}{$\begin{array}{l}\text { Overall } \\
(\%)\end{array}$} \\
\hline & $\mathbf{1}$ & 2 & 3 & 4 & 5 & & & \\
\hline To express my feelings & 17.9 & 11.5 & 22.6 & 23.3 & 24.7 & 3.25 & 1.41 & 65.0 \\
\hline $\begin{array}{l}\text { To get updates from my } \\
\text { followers }\end{array}$ & 7.7 & 10.4 & 17.2 & 34.3 & 30.3 & 3.69 & 1.22 & 73.8 \\
\hline To stay in touch & 10.4 & 9.1 & 20.2 & 28.6 & 31.6 & 3.62 & 1.30 & 72.4 \\
\hline $\begin{array}{l}\text { To get information on } \\
\text { trending issues }\end{array}$ & 6.4 & 3.7 & 9.5 & 27.8 & 52.5 & 4.16 & 1.15 & 83.2 \\
\hline To get financial help & 41.5 & 16.0 & 22.1 & 1.6 & 8.8 & 2.30 & 1.35 & 46.0 \\
\hline
\end{tabular}




\begin{tabular}{|c|c|c|c|c|c|c|c|c|}
\hline To socialize with friends & 7.5 & 6.5 & 21.2 & 39.6 & 25.3 & 3.69 & 1.14 & 73.8 \\
\hline $\begin{array}{l}\text { For business related } \\
\text { activities }\end{array}$ & 17.6 & 14.2 & 27.0 & 25.0 & 16.2 & 3.08 & 1.32 & 61.6 \\
\hline To get health advice & 19.9 & 20.2 & 30.0 & 17.5 & 12.5 & 2.82 & 1.28 & 56.4 \\
\hline $\begin{array}{l}\text { To pass time when I am } \\
\text { bored }\end{array}$ & 7.5 & 3.4 & 13.0 & 27.3 & 48.8 & 4.06 & 1.20 & 81.2 \\
\hline For entertainment or leisure & 5.1 & 4.4 & 9.5 & 24.1 & 56.9 & 4.23 & 1.12 & 84.6 \\
\hline To meet new people & 9.1 & 10.1 & 20.2 & 31.6 & 29.0 & 3.61 & 1.25 & 72.2 \\
\hline To feel less lonely & 16.2 & 14.2 & 23.6 & 22.0 & 24.0 & 3.23 & 1.39 & 64.6 \\
\hline To show off my lifestyle & 32.4 & 17.7 & 21.2 & 16.4 & 12.3 & 2.58 & 1.40 & 51.6 \\
\hline To learn new things & 6.7 & 6.4 & 19.2 & 28.6 & 39.1 & 3.87 & 1.20 & 77.4 \\
\hline Total & & & & & & 3.44 & 1.27 & 68.8 \\
\hline
\end{tabular}

\section{RQ3: What types of social support sought on social} networking sites among Twitter users?

There exist different types of social support to get from Twitter and this section strives to identify the types Twitter users, who form the respondents in this research endeavor. Table $3 \mathrm{a}$ shows the frequency and percentage of social support by respondents, who agree with either a single or multiple option range while Table $3 b$ shows the frequency and percentage of individual social support sought.
Table 3: Social support sought from Twitter by option range

\begin{tabular}{llll}
\hline $\begin{array}{l}\text { Social support } \\
\text { Twitter }\end{array}$ & sought & $\begin{array}{l}\text { from } \\
\text { uenc } \\
\text { y }\end{array}$ & $\begin{array}{l}\text { Perce } \\
\text { ntage }\end{array}$ \\
\hline Financial & 79 & 25.4 \\
Academic & 51 & 16.4 \\
Health & 31 & 10.0 \\
Moral & 55 & 17.7 \\
Business & 36 & 11.6 \\
Entertainment & 58 & 18.7 \\
Total & $\mathbf{3 1 0}$ & $\mathbf{1 0 0 . 0}$ \\
& & \\
\hline
\end{tabular}


Table 3 shows the different types of social support respondents seek from using Twitter. The most sought social support by respondents, who use the social networking site is the financial social support which 79 respondents $(25.4 \%)$ agreed to. The Entertainment and moral supports follow with $18.7 \%$ and $17.7 \%$ respectively.

RQ4: What is the relationship between online social networking and social support among Twitter users?

To find out the relationship between online social networking and social support among University of Ilorin undergraduate Twitter users, activeness on Twitter in terms of tweeting and re-tweeting was correlated with social support sought and gained on Twitter (see Table 4a). Also, social support sought and gained on Twitter was compared with number of followers the respondents have on Twitter (see Table 4b).

Table 4a: Correlation between activeness on Twitter and social support sought and gained from Twitter

\begin{tabular}{lll}
\hline Variable & ACT & SOC.SUP \\
\hline ACT & 1 & -.125 \\
& & .138 \\
& & 143 \\
SOC.SUP. & -.125 & 1 \\
& .138 & \\
& 143 &
\end{tabular}

$\mathrm{ACT}=$ Activeness on Twitter in terms of tweeting and retweeting, SOC.SUP. = Social support sought and gained from Twitter.

Table 4a shows that the correlation between activeness on Twitter in terms of tweeting and re-tweeting and social support sought and gained from the social networking site produced a weak negative and insignificant correlation $(r=-.125, \mathrm{p}=.138)$. This means there is no relationship between tweeting and retweeting on Twitter and seeking and obtaining social support from the same.
Table 4b: Correlation between followers on Twitter and social support sought and gained from Twitter

\begin{tabular}{lll}
\hline Variable & FOT & SOC.SUP \\
\hline FOT & 1 & $-.268^{* *}$ \\
& & .001 \\
& & 159 \\
SOC.SUP. &.$- .268^{* *}$ & 1 \\
& .001 & \\
& 159 &
\end{tabular}

**. Correlation is significant at the 0.01 level ( 2 tailed)

FOT $=$ Followers on Twitter, SOC.SUP. $=$ Social support sought and gained from Twitter

Table $4 \mathrm{~b}$ shows that there is a significant relationship between the number of followers one has on Twitter and the social support sought and gained on the networking platform $(r=-.268, \mathrm{p}=.001)$. This relationship is however, weak.

\section{DISCUSSION OF FINDINGS}

The objective of this study is to investigate the kind of social support sought and gained from using Twitter with focus on University of Ilorin undergraduates. A starting point was to establish the pattern of online networking among Twitter users. Findings show that majority of the respondents spend an average of 3- 4 days a week on Twitter. They also spend between 30 minutes and one hour daily on Twitter. However, majority of these Twitter users are not very active in terms of tweeting and re-tweeting. The implication is that majority of the respondents simply log into their Twitter accounts and observe without necessarily participating. This is inconsistent with Meng, Martinez, Holmstron and Chung's (2016) assertion that for users of social networking sites to benefit from the social support, they must be active users. Being passively engaged in online networking will, therefore, not provide the needed support. Majority of respondents 
also do not have a large following as most respondents have followers below 500 .

In terms of the reasons for online networking among Twitter users, findings show a moderately high level of agreement as to the reasons for using Twitter specifically for the purpose of entertainment or leisure, to get more information on trending issues or to pass time when they are bored. This result disagrees with Konetes and McsKeague's (2011) finding that students use Twitter and other channels to develop their identities, beliefs and stances on various issues such as politics, religion, and work, as well as to pioneer and develop intimate relationships. The study also revealed that the respondents use Twitter to learn new things consistent with findings by Notley (2010) which indicate that social networking helps in the school and universities to leverage and complement formal education activities and enhance learning outcomes.

To the extent that online social networking is believed to be the activities embarked on for purpose of social networking with people in that social circle and in this case, followers on Twitter, affirms Granovetter's (1973) weak social ties theory that deals with diffusing ideas and information. Weak ties imply social relations that require little investment, and they consist mostly of acquaintances or other loosely connected people rather than kin or close friends. Forms of weak social ties include "add friends," "follow the post," "mention," and "retweet". As an online platform that champion how people are connected online and clamor for and gain social support as evidenced by findings of this study do not prove otherwise. The results of the study prove that the respondents use Twitter for specific social supports. While much of the support is financial in nature, other supports come in form of moral and entertainment. Therefore, contrary to the belief that media audience could be passive, this study proves that there is high intention and actual use of Twitter to network with a view to achieving certain objectives primarily social support.

The eminent type of social support sought on social networking sites among Twitter users is clearly financial support as results of the study show. This suggest that respondents are often financially burdened and are predisposed to rendering or soliciting some financial assistance more than any other support they would like to seek or render to people they interact with online. Findings of this study contradicts those of Rai, Chen and Damiano (2013) which show that individuals commonly exchange emotional, informational, and selfesteem social support with informational support type sought and provided.

As regards the relationship between online social networking and social support among Twitter users, the findings show absence of relationship in the hours spent on Twitter and the magnitude of social support sought or gained. This means that social support from Twitter is not given simply because of its constant use or otherwise. This is inconsistent with findings by Chung, Yang and Chen (2014) which reveal that spending more time on social network sites, having more friends online, or using various features of social network sites, positively predict one's perceived and received social support, which in turn, lead to reduced stress and enhanced physical and psychological wellbeing. However, in the relationship between the extents of followings a Twitter user has and the level of social support sought and gained, result shows that there is a relationship. Although low, this relationship proves that the amount of connections a Twitter user is able to acquire influences the level of support the Twitter user gains.

\section{CONCLUSION AND RECOMMENDATIONS}

The conclusion that can be drawn from this study is that online networking is briskly supplanting traditional physical social networking and Twitter is a key platform that cannot be overlooked. This, however, does not suggest the extinction of physical connections of people. But the inconvenient truth people have to live with is that the changing media landscape will continue to shape human relationships, close or distant. Therefore, bracing up to the new offerings and actually keying into existing platforms like Tweeter which undergraduates

ISSN: 2456-7620

https://dx.doi.org/10.22161/ijels.62.12 
commonly use is never a disservice to self and humanity.

Against the backdrop of findings of this study, it is hereby recommended that:

Given the result that there is a correlation between the level of following and the magnitude of social support gained, Twitter users that seek social support should, therefore, endeavor to accumulate followers in order to maximally exploit the social support potential of Twitter.

On account that respondent predominantly use Twitter as a source of financial support, it is recommended that Twitter users should continue to seek other social support like moral and educative supportive messages that will remind them not to tie their selfworth primarily to social networking and validation from the online community.

Considering that financial support is one of the most sought supports on Twitter, parents, guardians, governments and other stakeholders should enhance financial capabilities of undergraduates in terms of scholarships and grants to augment their financial needs.

\section{REFERENCES}

[1] Apuke, D.O. \& Ayih, J. (2020). The acceptance and practice of citizen journalism in the North Eastern part of Nigeria. Malaysian Journal of Media Studies. 22 (1), 116.

[2] Baker, A. (2009). Phishing scams continue to plague social media sites. Available at http://www.wisebread.comphishing-scams-continueto-plague-social-media-sites. Accessed October 30, 2020.

[3] Balanarayan, N. T. (2009). Tweeting via SMS is in, the way it should be. Available at: www.dnaindia.com/scitech/report-tweeting-via-smsis-in-theway-it-should-be- 1324562.Accessed

October 15, 2020.

[4] Bello, B.S., Inuwa-Dutse, I. \& Heckel, R. (2020). Social media campaign strategies: Analysis of the 2019 Nigerian elections. Available at: http//www.researchgate.net3368. Accessed October 15, 2020.
[5] Biz, S. (2009). Twitter search for everyone!Available at:www.blob.Twitter.com/2009/Twitter-searcheveryone. Accessed October 22, 2020.

[6] Boyd, D.M. (2008).Let's define our terms: what is a social networking technology? apophenia: making connections where none previously existed."Available at:

http://zephoria.org/thoughts/archives/2008/01/08/lets_de fine_our.html.Accessed October 4, 2020.

[7] Chung, T.Y., Yang, C.Y. \& Chen, M.C, (2014). Online social support perceived by Facebook users and its effects on stress coping. European Journal of Econmics Management, 1, 196-216.

[8] DirVall, M. V. \& Kirwin, J.L. (2012). Using facebook to facilitate course-related discussion between students and faculty members. American Journal of Pharmaceutical Education, 76 (2),1-5.

[9] Donev, D., Pavlekovic, G. \& Lijana, Z.K. (2008). Socialnetworks and social support in creating and implementation of health promotion programmes. Health Promotion and Disease Promotion. Available at: https://doi.org/10.2390/biecoll-mhcp4-1.7.Accessed

September 12, 2020.

[10] Douglas, B. (2012). Birds: What is the new twitter bird logo's species? Available at:www.quora./Birds/What-isthe-new-Twitter-bird-logo'sspecies.Accessed October 22, 2020.

[11] Drew, O. (2012). Twitter poaches former Google exec Matt Derella as new director of agency business development. Available at: www.techcrunch.com/2012/10 /22/Twitterpoachesformergoogle-exec-mattderella-as-new-directorofagency-business-development. Accessed October 22, 2020.

[12] Easley, D. \& Kleinberg, J. (2010). Networks, crowds, and markets: Researching about a highly connected world. Cambridge: Cambridge University Press.

[13] Ellison, N. B. \& Boyd, D. (2013). Sociality through SNS. In W.H. Dutton (Ed.), The Oxford handbook of internet studies(pp. 151-172). Oxford: Oxford University Press.

[14] Fisher, D. (2011). Phishing, social networking attacks on the rise. Available at http://threatpost.com/enUS/blogsPhishing-socialnetworking-attack-rise-05/2011. Accessed September 12, 2020.

[15] Folorunso, O., Vincent, R.O., Adekoya, A.F \& Adewale, O.O. (2010). "Diffusion of innovation in social 
networking sites among university students." International Journal of Computer Science and Security (IJCSS), 4(3), 361-372.Accessed September 12, 2020.

[16] Fred, S. (2007). The 12-minute definitive guide to twitter.Available atwww.aol.com.Accessed October 30, 2020.

[17] Gottlieb, B.H.\& Bergen, A.E. (2010). Social support concepts and measures. Journal of Psychosomatic Research, 69, 511-520.

[18] Granovetter, M. S. (1973). The strength of weak ties. American Journal of Sociology, 78(6),1360-1380. DOI: 10.1086/225469. Accessed October 30, 2020.

[19] Hitwise (2007). Hitwise UK retail and social networking update.Available at:http://www.hitwise.co.uk/presscenter/hitwiseHS2004/retail.php.Accessed September 7, 2020.

[20] Hoffman, B.C. (2012). An exploratory study of a user's facebook security and privacy settings. Available athttp://cornerstone.lib.mnsu.edu/etds.Accessed August $14,2020$.

[21] Kavanaugh, A.L. \& Reese, D.D. (2005). Weak ties in networked communities. Information Society International Journal, 21(2), 119-131.

[22] Konetes, G.D. \& McKeague, M. (2011). The effects of social networking sites on the acquisition of social capital among college students: A pilot study. Available at:

https://www.researchgate.net/publication/265925171_Th e_effects_of_social_net

working_sites_on_the_acquisition_of_social_capital _among_college_students_A pilot study. Accessed September 18, 2020.

[23] Kwak, H., Lee, C., Park, H. \& Moon, S. (2010). What is twitter? A social network or a news media?Available at: http://an.kaist.ac.kr/traces/WW W2010.html.

[24] Lew, A. A. (2007).Twitter tweets for higher education. Web 2.0 teaching tools. Available at: hhttp://web20teach.blogspot.com/2007/08/twittertweets-for-higher- education.html. Accessed October 30, 2020.

[25] Li, J., Sheng, X.P. \& Wei, C.M. (2015). Empirical research on open access resources sharing behaviour from the perspective of weak ties (in Chinese). Library Forum, 87(2), 6-10.

[26] Liu, W., Sidhu, A., Beacom, A.M.\& Valente, T. W. (2017). Social network theory. Available at:https://www.researchgate.net/publication/316250457.
DOI: 10.1002/9781118783764.Accessed August 14, 2020.

[27] Manca, S. \& Ranieri, M. (2013). Is it a tool suitable for learning? A critical review of the literature on Facebook as a technology-enhanced learning environment. Journal of Computer-Assisted Learning, 29(6), 487-504.

[28] Maness, M. (2017). A theory of strong ties, weak ties, and activity behaviour: Leisure activity variety and frequency. Journal of the Transportation Research Board, 2665(1), 30-39. DOI: 10.3141/2665-04.

[29] McPherson, M., Smith-Lovin, L. \& Cook, J.M. (2001). Birds of a feather: Homophily in social networks. Annual Review of Sociology, 27(1), 415-444.

[30] Meng, J., Martinez, L., Holmstron, A.J. \& Chung, M. (2016). Research on social networking sites and social support from 2004 - 2015: A narrative review and direction for future research. Cyberpsychology, Behaviour, and Social Networking, 20(1), 1-8.

[31] Moore, H. (2013). Twitter files for IPO in first stage of stock market launch. Available at: www.theguardian.com/technology/.Accessed September $14,2020$.

[32] Ngozi, J.O. \& Mustapha, A.A. (2019)."Perception of social media credibility and online political participation by young adults in Ibadan metropolis. Novena Journal of Communication, 11, 25-37.

[33] Notley, T.M. (2009). Young people, online networks, and social inclusion. Available at: DOI:10.1111J.10836101.2009.014870.X. Accessed October 30, 2020.

[34] Omekwu, C.O., Eze, H.N. \& Odoh, J.N. (2014). The use of social networking sites among the undergraduate students of University of Nigeria,Nsukka. Available at http://digitalcommons.unl.edu/libphilprac/1195. Acce ssed August 17, 2020.

[35] Onomo, A.A. (2012, January 15). People power. 15 social media. The Guardian, p. 38.

[36] Rai, J.R., Chen, Y. \& Damiano, A. (2013). Health organisations providing and seeking social support: A twitter-based content analysis. Cyberpsychology, Behaviour, Networking, 16, 669-673.

[37] Rosman, K. (2009). Sarah Palin's Facebook alter-ego gets found out.Available at: http://blogs.wsj.com/speakeasy/2009/08/13/sarah-palinsfacebook- alter-ego-gets- foundout/. Accessed September 14, 2020.

[38] Sharone, O. (2014). Social capital activation and job searching: Embedding the use of weak ties in the 
American institutional context. Work \& Occupations, 41(4), 409-439.

[39] Siemens, G. \& Weller, M. (2011). Higher education and the promises and perils of socialnetwork. Revista de Universidady Sociedad del Conocimiento (RUSC), 8(1), 164-170.

[40] Timm, C.\& Perez, R. (2010). Seven deadliest social network attacks. Burlington, MA:Syngress Publishing, inc.

[41] Uchino, B.N. (2004).Social support and physical health: Understanding the health consequences of relationships. New Haven: Yale University Press.

[42] Valentine, G. \& Holloway, S. (2002). Cyberkids? Exploring children's identities and social networks in on-line and offline worlds. Annals of the Association of American Geographers, 92(2), 302-309.

[43] Wei, L., Xu, H., Wang, Z., Dong, K., Wang, C. \& Fang, S. (2016). Topic detection based on weak tie analysis: A case study of LIS research. Journal of Data and Information Science, 1(4), 81-101. DOI: 10.20309jdis.201626. Accessed October 30, 2020. 